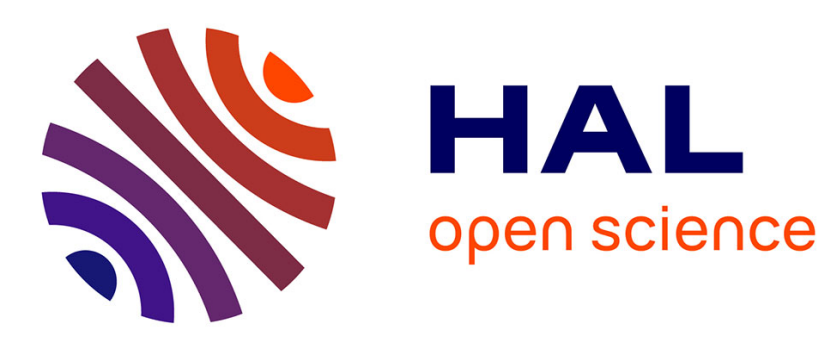

\title{
The efficiency of maize farming in Malawi. A bootstrapped translog frontier
}

\author{
Hardwick Tchale, Johannes Sauer
}

\section{To cite this version:}

Hardwick Tchale, Johannes Sauer. The efficiency of maize farming in Malawi. A bootstrapped translog frontier. Cahiers d'Economie et de Sociologie Rurales, 2007, 82-83, pp.33-56. hal-01201145

\section{HAL Id: hal-01201145 \\ https://hal.science/hal-01201145}

Submitted on 17 Sep 2015

HAL is a multi-disciplinary open access archive for the deposit and dissemination of scientific research documents, whether they are published or not. The documents may come from teaching and research institutions in France or abroad, or from public or private research centers.
L'archive ouverte pluridisciplinaire HAL, est destinée au dépôt et à la diffusion de documents scientifiques de niveau recherche, publiés ou non, émanant des établissements d'enseignement et de recherche français ou étrangers, des laboratoires publics ou privés. 


\section{The efficiency of maize farming in Malawi.}

A bootstrapped translog frontier

Hardwick TCHALE

Johannes SAUER 


\section{Hardwick TCHALE *, Johannes SAUER **}

\section{Efficacité de la culture du maïs au Malawi. Une approche par la méthode de la frontière translog bootstrappée}

Résumé - On mesure le niveau et les déterminants de l'efficacité technique des petits producteurs de maïs en utilisant la méthode de frontière stochastique translog bootstrappée dont la validité est vérifiée a posteriori. Les résultats montrent que les plus hauts niveaux d'efficacité technique sont obtenus par les agriculteurs utilisant une fertilisation intégrée de la culture plutôt que des fertilisants uniquement minéraux. Concernant les variables de politique utilisées dans l'analyse, l'accès aux marchés des input et output, l'offre de crédit et les services complémentaires influencent considérablement l'efficacité technique des petits agriculteurs. Il est souhaitable d'approfondir ces dimensions de la politique publique avant d'aborder l'efficacité de l'agriculture malawienne et ses conséquences sur la pauvreté en garantissant une gestion durable de la fertilité du sol.

Mots-clés : petites exploitations agricoles, méthode de frontière bootstrappée, gestion de la fertilité du sol, Malawi

\section{The efficiency of maize farming in Malawi. A bootstrapped translog frontier}

Summary - We measure the level and determinants of technical efficiency of maize based smallholder farmers using a bootstrapped translog stochastic frontier that is a posteriori checked for functional consistency. The results show that higher levels of technical efficiency are obtained when farmers use integrated soil fertility options compared to the use of inorganic fertilizer only. With respect to the policy variables considered in the analysis, access to agricultural input and output markets, credit provision and extension services strongly influence smallholders' technical efficiency. There is a need to strengthen these public policy issues in order to effectively address the efficiency of Malawian agriculture and its impact on poverty by ensuring sustainable soil fertility management.

Key-words: smallbolder agriculture, bootstrapped frontier, soil fertility management, Malawi

* Worldbank and University of Malawi, Bunda College,P.O. Box 219, Lilongwe, Malawi

e-mail: btchale@worldbank.org

** University of Copenhagen, Institute for Food and Resource Economics, Rolighedsvej 25,

1958 Copenhagen, Denmark

e-mail:js@foi.dk 
$\mathrm{M}$ ALAWIAN smallholder agriculture is dominated by maize production and is already operating at its land frontier with very little or no scope to increase the supply of land to meet the growing demand for food (Smale and Jayne, 2003). A further expansion of the crop area which was the major source of maize output growth till the 1980s, is no longer possible due to population pressure. Thus, the only plausible solutions to increase food production lie in raising the productivity of land by improving the technical efficiency and/or through technological improvements. Efficiency gains will have a positive impact on raising farm incomes of these largely resource poor farmers (Kydd, 1989; Smale and Jayne, 2003 ; Chirwa, 2003).

The relative role of efficiency and productivity with respect to smallholder agriculture is subject of a long debate in development economics (see e.g. Schultz, 1964 or Barrett, 1997). Hence, the paper analyses the technical as well as scale efficiency of hybrid maize production among smallholder farmers and identifies the factors that explain the variation in the efficiency of individual smallholder farmers. We focus on maize production as maize is crucial for food security reasons as most of the smallholder farms largely produce for own consumption purposes with a relatively low level of market integration (see e.g. Edriss et al., 2004 and Sherlund et al., 2002). The relationships between efficiency, policy indicators and farm-specific practices have not been widely studied in Malawi. An understanding of these relationships would provide policy makers with information to design programmes that can contribute to increasing food production potential among smallholder farmers who produce the bulk of the country's food.

Only a few studies measured the efficiency among Malawian smallholder farmers. Most of them show a rather narrow focus in terms of data sampling or - more important - in adhering to the regularity requirements by microeconomic theory with respect to the estimated frontier. The rest of the paper is arranged as follows: the next section presents the policy environment in Malawi since the 1980s and its general impact on the development of smallholder agriculture. This is followed by a review of related studies on factors influencing technical efficiency of smallholder farming systems in Malawi as well as the formulation of the basic research hypotheses. Then we present a brief discussion of stochastic frontier analysis as the base for the analytical framework used in this study, followed by the presentation of the data set used in the analysis and the discussion of the empirical results. We finally conclude with the main findings and potential policy implications.

\section{The agricultural policy environment and its impact on smallholder farmers}

Since 1981 the Government of Malawi has implemented reforms aiming at removing market distortions in order to create a conducive environment and to improve the access to productive resources for all groups of smallholder farmers. A significant element of all Structural Adjustment Program (SAP) loans Malawi accessed from 1981 to the early 1990s was to ensure an appropriate price policy in 
order to provide adequate incentives to producers and to expand the role of the private sector in the marketing of smallholder crops (Bhalla et al., 2000). Hence, these policy programs aim at targeting allocative as well as technical efficiency by enabling farmers to enhance their production technology beside purchasing higher value inputs ${ }^{1}$.

Despite the deregulated production and marketing environment, the attainment of improved technical efficiency still remains largely elusive among the majority of the smallholder farmers. Available studies suggest little improvements or even a stagnation in terms of productivity gains with respect to many smallholder crops, and as a result the goal of self-sufficiency still remains largely unattained (Chirwa, 2003 ; Zeller et al., 1998). Taking the case of the most important smallholder crops (maize and tobacco) all indicators point to a mixed trend in productivity development. As observed by Chirwa (2003), despite government support ${ }^{2}$ maize efficiency has either marginally improved or remained stagnant since the 1980s until the 1990s. In the case of tobacco, the substantial productivity gains attained in the early 1990s, more especially after the repeal of the Special Crops Act, have been reversed as the average tobacco yield has been declining since the mid-1990s.

Many studies relate the lower levels of technical efficiency to the structural reforms (Owusu and Ngambi, 2002; GOM, 2002). However, there is a need for agricultural policy makers to get empirical insight in the levels of smallholder technical efficiency as well as the different determining factors in order to be able to more effectively address their performance in the post-reform era.

\section{Technical efficiency studies among smallholder farmers}

Technical efficiency is a component of economic efficiency and reflects the ability of a farmer to maximize output from a given level of inputs (i.e. output-orientation). Theoretical developments in measuring (output-oriented) technical efficiency started with the works of Debreu (1951 and 1959). There is a growing literature on the technical efficiency of African agriculture so far. Recent notable studies focus on SubSaharan Africa (SSA) including Heshmati and Mulugeta (1996), Fulginiti and Perrin (1998), Seyoum et al. (1998), Townsend et al. (1998), Weir (1999), Weir and Knight (2000), Mochebelele and Winter-Nelson (2000), Chirwa (2003), Sherlund et al. (2002) and Okike et al. (2004). Most of these studies report a low to moderate technical efficiencies ranging from as low as $0.24-0.36$ among farmers in Lesotho to 0.56 in Ethiopia, thus confirming the evidence that most countries in the developing world in general and SSA in particular still experience relatively low efficiency levels

1 A more detailed discussion of Malawi's agricultural policy issues is provided in Dorward et al. (2004a and 2004b) and Kydd and Dorward (2001).

2 Malawi with support mainly from the UK Department for International Development (DFID) has been implementing a Targeted Inputs Programme which involves the distribution of free fertilizer, maize and legume seed to all poor smallholder farmers since 1998/99. 
in agriculture. Among the factors that influence technical efficiency, farmers' education, extension, credit, market access, farmers' access to improved technologies through the market or public policy interventions and land holding size, have been given priority in most of the studies. Most studies report a positive impact of these variables on technical efficiency (see also Tian and Wan, 2000; Reinhard et al., 2002). However, the relationship between farm size and efficiency has not been straightforward (see for a detailed discussion e.g. Kalaitzadonakes et al., 1992): While one would expect a positive relationship between productivity and economies of scale due to the economies of scale argument, most studies so far conclude in an inverse or only weak positive relationship between scale and efficiency (Townsend $e t$ al.,1998; Heshmati and Mulugeta, 1996).

Some socio-economic variables such as gender of the farmers do not significantly influence efficiency, as reported by Mochebelele and Winter-Nelson (2000) in the case of Lesotho. However, Alderman et al. (1995) found that gender plays an important role especially in SSA where the participation of women in agriculture is higher than for men. Other studies have extended the specification of the variables affecting efficiency by including environmental and ecological variables to avoid omitted variable bias leading to over-estimation of technical inefficiency (Sherlund $e t$ al., 2002 ; Okike et al., 2004). This is particularly important because most farming systems in SSA are rain watered and production decisions are greatly influenced by environmental factors such as the frequency of rainfall.

However, one critical consequence of the aforementioned policy measures has been an increase in fertilizer prices relative to maize grain prices. Consequently most farmers over the past decade have continued to over-exploit the natural soil fertility. This is because the improved maize varieties released by the National Agricultural Research (i.e. MH17 and MH18) proved to yield more than local maize without fertilizer at the seed prices that prevailed through the early 1990s. This implies that it made economic sense for farmers to grow hybrids even if they could not apply fertilizer (Heisey and Smale, 1995). This has resulted in soil fertility mining, leading to unsustainability, as the inherent soil fertility is no longer capable of supporting crop growth at a rate that is required to feed the growing population. This calls for concerted efforts to promote smallholder soil fertility management using relatively more sustainable options such as integrated soil fertility management (ISFM), i.e. involving incorporation of grain legumes and inorganic fertilizer in maize production systems. In general ISFM refers to an integrative use of inherent soil nutrient stocks, locally available soil amendments and mineral fertilizers to increase the productivity of the land while maintaining or enhancing soil fertility (see e.g. Pieri, 1989 or Breman and Sissoko, 1998). An increase in output through agricultural intensification generally requires the use of mineral fertilizers leading to serious damages to soil fertility (i.e. acidification) and yield decline in the long term. On the other hand the nutrient content by organic sources is relatively low and not abundantly available to the farmer. Hence, a combination of both inorganic and organic fertilizers has been suggested as a superior remedy for soil fertility in SubSaharan Africa. Here the inorganic fertilizer provides the nutrients and the organic fertilizer increases soil organic matter status, the structure of the soil and its 
buffering capacity in general. Moderate applications of minerals ensure balanced plant nutrition and the maintenance of the soil fertility (see e.g. Breman and Sissoko, 1998).

From a methodological point of view one critical observation is that most of these studies have neither a posteriori tested nor a priori imposed economic regularity conditions as monotonicity in inputs (or input prices and output) and quasiconcavity (concavity) on the estimated production (or cost) functions. It is therefore likely that most of the estimated functions may have locally or even globally violated the economic regularity conditions, thus invalidating the policy implications that may have been drawn from the studies (see e.g. Sauer, 2006) ${ }^{3}$. Secondly, one of the factors that is largely responsible for the increased inefficiency of smallholder farmers is the soil fertility status. This is critical because external input application to food crops such as maize is exceptionally low among smallholder farmers, more especially in SSA, due to the increase in the real prices of fertilizers relative to crop prices. Our study therefore aims at assessing the implications of alternative soil fertility management options such as integrated soil fertility management (ISFM) for technical efficiency, developed by researchers specifically for smallholder farmers. Soil fertiliy management practices can be modelled as determining the production possibility space of the farms in the sample in the sense of an input to production. On the other hand such soil management practices can be considered as inefficiency explaining factors. On the basis of these earlier findings we formulate the following research hypotheses to be explored in the subsequent analysis :

(1) It can be assumed that farms applying integrated soil fertility management practices show a higher technical efficiency than farms applying inorganic fertilizer only.

(2) Due to previous evidence and the rather small scale of the farms in the sample it is expected that the average farm in the sample exhibits a considerable scale inefficiency.

(3) Beside a significant efficiency effect of soil fertility practices we assume a significant influence of precipitation and the prevailing soil conditions.

(4) We suppose that the soil fertility practice applied is more adequately modelled by an explaining variable with respect to the variation in inefficiency over different farms.

\section{Modeling framework}

Different (deterministic as well as stochastic, parametric as well as non parametric) techniques to measure relative efficiency are extensively described in the literature (see e.g. Coelli et al., 1998 or Kumbhakar and Lovell, 2000). As the stochastic frontier approach is capable of capturing measurement error and other

3 Efficiency estimates infered from a convex production function region are not based on the assumption that producers aim at maximizing output. 
statistical noise influencing the shape and position of the production frontier, we consider it as superior in an agricultural production context largely influenced by randomly exogenous shocks as e.g. climatic influences. However, the stochastic approach to efficiency measurement is subject to prior decisions on the distributional form of the inefficiency component of the error term as well as the modeling of the underlying technology. The latter has to be specified by a particular functional form adhering to theoretical consistency as well as flexibility (see Sauer, 2006). In the following analysis, we apply a stochastic error components approach to map the process of maize production in Malawi by using the flexible functional form of a translog production function. Because of missing scarcity signals (i.e. absence of real prices) as a consequence of lacking input and output markets, small scale farming in Malawi seems to be adequately modeled by the behavioural assumption of output maximisation. Hence, an output orientation of the frontier was chosen here. Our maize production frontier can be formulated as a stochastic maize production frontier in a cross-sectional context following :

$$
y_{i}=f\left(x_{i} ; \beta\right) * \exp \left\{v_{i}\right\} * T E_{i}
$$

where $\left[f\left(x_{i} ; \beta\right) * \exp \left\{v_{i}\right\}\right]$ is the stochastic production frontier consisting of the deterministic part $f\left(x_{i} ; \beta\right)$ common to all maize producers in the sample and a producer-specific $\exp \left\{v_{i}\right\}$ capturing the effect of random shocks on each maize producer. Technical efficiency is then simply defined by (2) :

$$
T E_{i}=\frac{y_{i}}{f\left(x_{i} ; \beta\right) * \exp \left\{v_{i}\right\}}
$$

as the ratio of observed maize output to maximum feasible maize output in an environment characterized by $\exp \left\{v_{i}\right\}$.

\section{The empirical model}

\section{Basic model}

By applying a translog production function the stochastic frontier in (1) is described by :

$$
\ln y_{i}=\beta_{0}+\sum_{k=1}^{n} \beta_{k} \ln x_{k i}+\frac{1}{2} \sum_{k=1}^{m} \sum_{l=1}^{m} \beta_{k l} \ln x_{k i} \ln x_{l i}+v_{i}-u_{i}
$$

where $: i=$ producer $1, \ldots, m ; k, l=$ input $1, \ldots, m ; v$ denotes the traditional error component and $u$ the non-negative inefficiency component. $v_{i}$ is assumed to be iid, symmetric and distributed independently of $u_{i}$. Thus the error term $\varepsilon_{i}=v_{i}-u_{i}$ is asymmetric, since $u_{i}=0$. Symmetry is imposed by constraining (3) according to: $\beta_{k l}=\beta_{l k}$. By a simultaneous one-stage estimation approach the inefficiency $\mu_{i}$ estimates are related to the exogenous factors of maize production by: 


$$
\mu_{i}=\gamma_{0}+\gamma_{r} \sum_{r=1}^{s} z_{r i}
$$

where $z_{i}$ is a vector of determinants of inefficiency such as land husbandry practices (i.e. weeding, date of planting, cropping pattern, manure type, and manure quantity ${ }^{4}$ ), climatic and soil characteristics (i.e. rainfall, soil depth, bulk density, organic matters, and total nitrogen in the soil) as well as regional location (i.e. Agricultural Development Zone of Lilongwe, Blantyre or Mzuzu) and finally individual characteristics (i.e. gender and age of the farmer as well as years of education and size of the farm household) as explained in the next section as well as table 1. The maximum likelihood estimates for all parameters of the stochastic frontier as well as the inefficiency effects model are simultaneously estimated ${ }^{5}$. The underlying econometric model specification follows the one introduced by Battese and Coelli (1995).

\section{Scale efficiency}

In order to measure beside technical also scale efficiency on farm level we estimate the model specified in (3) and (4) in a constant as well as variable returns to scale specification. We impose symmetry in inputs by $\beta_{j k}=\beta_{k j}$, homotheticity as well as homogeneity of degree 1 by $\sum_{j} \beta_{j}=1, \sum_{j} \sum_{k} \beta_{j k}=0$. This enables us to reveal evidence on the scale efficiency of farm $i$ by simply following

$$
s e_{i}=t e_{i}^{c s s} / t e_{i}^{2 n s}
$$

where se denotes scale efficiency and te technical efficiency, crs and vrs refer to the constant returns and the variable returns specification respectively (see e.g. Coelli et al., 1998 and Karagiannis and Sarris, 2005).

4 The quantity of manure is treated as an inefficiency effect as the majority of small-scale farms in this production setting and in our sample do not apply such manure at all. Hence, treating the quantity of manure as a productive input would be misleading in this specific context.

5 The maximum likelihood frontier estimation procedure contained in STATA/SE 8.0 was applied for the model estimations. The variance parameters are estimated by following the reparameterisation $\sigma_{s}^{2}=\sigma_{v}^{2}+\sigma^{2}$ and $\gamma=\sigma^{2} / \sigma_{s}^{2}$ with $\gamma \in[0 ; 1]$. The mean technical efficiency of the $i$-th maize farmer is estimated via the point estimator: $T E_{i}=E\left(\exp \left\{-u_{i}\right\} \mid \varepsilon_{i}\right)=\left\lfloor\frac{1-\Phi\left(\sigma_{*}-\mu_{*_{i}} / \sigma_{*}\right)}{1-\Phi\left(-\mu_{*_{i}} / \sigma_{*}\right)}\right\rfloor * \exp \left\{-\mu_{*_{i}}+1 / 2 \sigma_{*}^{2}\right\}$ (see e.g. Kumbhakar and Lovell, 2000). 


\section{Hypotheses testing}

We statistically test for the scale specification of our model (hypothesis i) by applying a standard likelihood ratio testing procedure. We further check for the adequacy of the chosen translog specification by testing it against the linear specification of a CobbDouglas production frontier (hypothesis ii). Further the stochastic frontier specification is tested against the mean response function (hypothesis iii) and finally we test for the joint significance of the efficiency effects incorporated (hypothesis iv).

\section{Functional consistency}

In the case of a (single output) production frontier monotonicity requires positive marginal products with respect to all inputs and thus non-negative elasticities. With respect to the translog production frontier model in (3) the marginal product of input $i$ is obtained by multiplying the logarithmic marginal product with the average product of input $i$. Thus the monotonicity condition given holds for our translog specification if the following equation is true for all inputs:

$$
\frac{d q}{d x_{i}}=\frac{q}{x_{i}} \frac{d \ln q}{d \ln x_{i}}=\frac{q}{x_{i}}\left(\alpha_{i}+\sum_{j=1}^{n} \beta_{i j} \ln \left(x_{i}\right)\right)>0
$$

Since both $q$ and $x_{i}$ are positive numbers, monotonicity depends on the sign of the term in parenthesis, i.e. the elasticity of $q$ with respect to $x_{i}{ }^{6}$. By further adhering to the law of diminishing marginal productivities, marginal products, apart from being positive should be decreasing in inputs implying the fulfillment of the following expression :

$$
\frac{d^{2} q}{d x_{i}^{2}}=\left\lfloor\alpha_{i i}+\left(\alpha_{i}-1+\sum_{j=1}^{n} \beta_{i j} \ln x_{j}\right)\left(\alpha_{i}+\sum_{j=1}^{n} \beta_{i j} \ln x_{j}\right)\right\rfloor\left(\frac{q}{x_{i}^{2}}\right)<0
$$

Again, this depends on the nature of the terms in parenthesis. These should be checked a posteriori by using the estimated parameters for each data point. However, both restrictions (i.e. $\left(\partial q / \partial x_{i}\right)>0$ and $\left.\left(\partial^{2} q / \partial x_{i}{ }^{2}\right)<0\right)$ should hold at least at the point of approximation. At this point, positive marginal products for each input require $\beta_{j}>0 \forall j$. On the other hand, diminishing marginal productivities require $\beta_{j}\left(\beta_{j}-1\right)<0 \forall j$, which is true always and only if $0<\beta_{j}<1 \forall j$.

The necessary and sufficient condition for a specific curvature consists in the semi-definiteness of the bordered Hessian matrix as the Jacobian of the derivatives

6 If it is assumed that markets are competitive and factors of production are paid their marginal products, the term in parenthesis equals the input $i$ 's share of total output, $s_{i}$. 
$\partial q / \partial x_{i}$ with respect to $x_{i}$ : if $\nabla^{2} Y(x)$ is negatively semi-definite, the production function is quasi-concave, where $\nabla^{2}$ denotes the matrix of second order partial derivatives with respect to the normalized translog production model. The Hessian matrix is negative semi-definite at every unconstrained local maximum ${ }^{7}$. The conditions of quasi-concavity are related to the fact that this property implies a convex input requirement set (see in detail e.g. Chambers, 1988). Hence, a point on the isoquant is tested, i.e. the properties of the corresponding production frontier are evaluated subject to the condition that the amount of production remains constant. With respect to the translog production function curvature depends on the specific input bundle $X_{i}$ as the corresponding bordered Hessian $B H$ for the 3 input case shows :

$$
B H=\left(\begin{array}{llll}
0 & b_{1} & b_{2} & b_{3} \\
b_{1} & b_{11} & b_{12} & b_{13} \\
b_{2} & b_{21} & b_{22} & b_{23} \\
b_{3} & b_{31} & b_{32} & b_{33}
\end{array}\right)
$$

where $b_{i}$ is given in (6), $b_{i i}$ is given in (7) and $b_{i j}$ is :

$$
\frac{d^{2} q}{d\left(x_{i} x_{j}\right)}=\left[\alpha_{i j}+\left(\alpha_{i}+\sum_{j=1}^{n} \beta_{i j} \ln x_{j}\right) *\left(\alpha_{j}+\sum_{i=1}^{n} \alpha_{i j} \ln x_{i}\right)\right] *\left(\frac{q}{x_{i} x_{j}}\right)<0
$$

For some input bundles quasi-concavity may be satisfied but for others not and hence what can be expected is that the condition of negative semi-definiteness of the bordered Hessian is met only locally or with respect to a range of input bundles. The respective bordered Hessian is negative semi-definite if the determinants of all of its principal submatrices are alternate in sign, starting with a negative one (i.e. $(-1)^{j} D_{j}$ $\geq 0$ where $D$ is the determinant of the leading principal minors and $j=1,2, \ldots, n)^{8}$. Hence, with respect to our translog production frontier model it has to be checked a posteriori for every input bundle that monotonicity and quasi-concavity hold. If these theoretical criteria are jointly fulfilled the obtained efficiency estimates are consistent with microeconomic theory and consequently can serve as empirical evidence for possible policy measures. Hence by a second analytical step we finally (a posteriori) check the theoretical consistency of our estimated efficiency model by verifying that the first derivatives of (5) are positive (monotonicity), the own second derivatives are negative and finally the Hessian is negative semi-definite (quasiconcavity).

7 Hence, the underlying function is quasi-concave and an interior extreme point will be a global maximum. The Hessian matrix is positive semi-definite at every unconstrained local minimum.

8 Determinants of the value 0 are allowed to replace one or more of the positive or negative values. Any negative definite matrix also satisfies the definition of a negative semi-definite matrix. 


\section{Bootstrapping}

To test finally for the robustness of our estimates obtained by (3) and (4) we further apply a simple stochastic resampling procedure based on bootstrapping techniques (see e.g. Efron, 1979 or Efron and Tibshirani, 1993). This seems to be necessary as our cross-sectional data sample consists of a (rather) limited number of observations. If we suppose that $\hat{\Psi}_{n}$ is an estimator of the parameter vector $\Psi_{n}$ including all parameters obtained by estimating (3) and (4) based on our original sample of 252 observations $X=\left(x_{1}, \ldots, x_{n}\right)$, then we are able to approximate the statistical properties of $\hat{\Psi}_{n}$ by studying a sample of 1000 bootstrap estimators $\hat{\Psi}_{n}(c)_{m}, c=1, \ldots, C$. These are obtained by resampling our maize farm observations - with replacement - from $X$ and recomputing $\hat{\Psi}_{n}$ by using each generated sample. Finally the sampling characteristics of our vector of parameters is obtained from

$$
\hat{\Psi}=\left[\hat{\Psi}_{(1) m}, \ldots, \hat{\Psi}_{(1000) m}\right]
$$

As is extensively discussed by Horowitz (2001) or Efron and Tibshirani (1993), the bias of the bootstrap as an estimator of $\hat{\Psi}_{n}, B_{\tilde{\psi}}=\tilde{\Psi}_{n}-\hat{\Psi}_{n}$, is itself a feasible estimator of the bias of the asymptotic estimator of the true population parameter $\Psi_{n}{ }^{9}$. This holds also for the standard deviation of the bootstrapped empirical distribution providing a natural estimator of the standard error for each initial parameter estimate. By using a bias corrected boostrap we aim to reduce the likely small sample bias in the initial estimates.

\section{Data}

The main data set used for the analysis is the farm household and plot level data collected from nearly 376 households (or 573 plots) in Mzuzu, Lilongwe and Blantyre Agricultural Development Divisions (ADD) from May to December $2003^{10}$. A two-stage stratified random sampling approach was used to draw the

9 Hence the bias-corrected estimator of $\psi_{n}$ can be computed by $\hat{\psi}_{n}-B_{\tilde{\psi}}=2 \hat{\psi}-\tilde{\psi}$.

10 Malawi's agricultural extension administration is channeled through a hierarchy of levels of agro-ecological zones starting with an Agricultural Development Division (ADD) at a regional level, a Rural Development Project (RDP) at a district level and an Extension Planning Area (EPA) at a local level. EPAs are further sub-divided into sections that are manned by frontline extension staff that are in direct contact with farmers. There are eight ADDs, 28 RDPs and over 150 EPAs. Our choice of the three ADDs was purposefully done for two main reasons: (i) these are well representative of Malawi's diverse farming systems, in terms of production potential and heterogeneity in resource endowments, more especially land, with Blantyre ADD being the most land constrained, (ii) these agro-ecological zones have adequate numbers of smallholder farmers who have been involved in soil fertility improvement programmes, involving both public institutions and non-governmental organizations for over a decade. 
sample. In each ADD, the sampling focused on one Rural Development Project (RDP) from which two Extension Planning Areas (EPA) were chosen, one in an easily accessible area and another from a remote area. A representative sample for each enumeration area was obtained through a weighting system in which district population and population density were considered.

Table 1 presents the definitions of the variables used in the analysis, their measurement units and their descriptive statistics. For the estimation of efficiency hybrid maize has been considered because of its high yield response to inputs compared to local varieties. While many farmers still grow local maize varieties, there has been a significant increase in the number of farmers that have been growing either open pollinated varieties (OPV) or hybrids. To this background the choice of hybrid maize farmers seems to be justified and relevant for future smallholder maize farming in Malawi. The main variable inputs used in maize production include fertilizer, labour, seed, and land. In analyzing the factors that influence efficiency, we have included land husbandry practices, climate and soil related characteristics, and selected policy and regional variables (i.e. the location of the farm in one of the ADD Mzuzu, Lilongwe, or Blantyre) as well as individual farmer characteristics. The specification of most of these is based on the relevant literature (Seyoum et al., 1998 ; Chirwa, 2003 ; Helfand and Levine, 2004 ; Okike et al., 2004). Among the policy related variables, access to credit, input/output markets and extension services feature highly in most policy discussions regarding agricultural performance. As discussed earlier, Malawi has gone through a number of challenges in the previous decade that have greatly influenced farmers' access to such public policy support. For example, there has been a change in the administration of smallholder credit from a state-sponsored Smallholder Agricultural Credit Administration (SACA) to a more private oriented credit institution, the Malawi Rural Finance Company (MRFC). Marketing of agricultural inputs and outputs has been completely deregulated from the state-sponsored parastatal, the Agricultural Development and Marketing Corporation (ADMARC), which is also undergoing substantive changes towards commercialization. There has also been a drastic reduction in public support with respect to the provision of agricultural extension ${ }^{11}$. As outlined in the previous section on modelling a binary dummy has been included for the soil fertility management option adopted by the farmers with respect to the total frontier estimation. We differentiate between integrated management, which involves the use of inorganic fertilizer and the low-cost 'best-bet' options such as grain legumes e.g. groundnuts (Arachis hypogea), soybeans (Glycine max.), pigeon peas (Cajanas cajan) and velvet beans (Mucuna pruriens) and the use of inorganic fertilizer only as the main input.

11 In aggregate terms, the public expenditure in agriculture has declined from about $12 \%$ of total public expenditure in the early 1990s to about 5\% after 2000 (Fozzard and Simwaka, 2002). 
Table 1. Descriptive Statistics

\begin{tabular}{|c|c|c|c|}
\hline \multirow{2}{*}{ Variable } & \multirow{2}{*}{ Description } & \multicolumn{2}{|c|}{$(N=252)$} \\
\hline & & Mean & Std \\
\hline YIELD & Hybrid Maize yield (kg/ha) & 914.98 & 886.67 \\
\hline \multicolumn{4}{|l|}{ Production Factors } \\
\hline FERTILIZER & Fertilizer (kg/ha) & 30.86 & 38.32 \\
\hline LABOUR & Labour (mandays/month/ha) & 57.55 & 34.81 \\
\hline SEED & Seed $(\mathrm{kg} / \mathrm{ha})$ & 55.74 & 15.61 \\
\hline LAND & Land (ha) & 0.57 & 0.48 \\
\hline \multicolumn{4}{|c|}{ Inefficiency Determinants } \\
\hline ISFM & Soil Fertility Management (1 = ISFM; 0 = Inorg) & 0.57 & 0.49 \\
\hline WEEDING & Frequency of Weeding (times per fallow period) & 1.38 & 0.84 \\
\hline PLANTING & Date of Planting ( $1=$ early; $0=$ later than first rains $)$ & 1.67 & 0.47 \\
\hline RAIN & Rainfall in $\mathrm{mm}$ & 899.04 & 59.01 \\
\hline$E X T \_F R E Q$ & Frequency of Extension Visits per month & 0.76 & 1.01 \\
\hline CREDIT & Access to Credit $(1=$ yes; $0=$ no $)$ & 0.36 & 0.48 \\
\hline MACCESS & Market Access ( 1 = accessible; 0 = remote $)$ & 0.38 & 0.49 \\
\hline SOILDEPTH & Depth of the Soil (in cm) & 15.91 & 2.59 \\
\hline BULKDNY & Bulk Density (g/cm3) & 1.63 & 0.31 \\
\hline ORGANM & Organic Matter in the Soil ( $\%$ of total) & 1.05 & 0.44 \\
\hline TOTNITRO & Total Nitrogen in the Soil ( $\%$ of total) & 0.10 & 0.04 \\
\hline CROPPATRN & Cropping Pattern ( $1=$ monocropping, $0=$ intercropping $)$ & 0.23 & 0.42 \\
\hline SEX & Gender of the Farmer $(1=$ male, $0=$ female $)$ & 0.61 & 0.49 \\
\hline$A G E$ & Age of the Farmer (years) & 44.67 & 16.48 \\
\hline$E D U$ & Education of the Farmer (years) & 3.27 & 1.38 \\
\hline$H H$ & Size of the Household (n) & 5.29 & 2.33 \\
\hline MAN_ANI & Animal Manure applied $(1=$ yes, $0=$ no $)$ & 0.03 & 0.17 \\
\hline MAN_GREEN & Green Manure applied $(1=$ yes, $0=$ no $)$ & 0.02 & 0.15 \\
\hline MAN_COMP & Compost Based Manure applied $(1=$ yes, $0=$ no $)$ & 0.12 & 0.32 \\
\hline$M N R Q U$ & Amount of Manure Applied (in tons) & 0.56 & 1.35 \\
\hline$A D D L$ & Agricultural Development Zone Lilongwe ( $1=$ yes; $0=$ no) & 0.23 & 0.42 \\
\hline$A D D B$ & Agricultural Development Zone Blantyre ( $1=$ yes; $0=$ no) & 0.51 & 0.50 \\
\hline
\end{tabular}

Source : own survey (2003) 


\section{Results and discussion}

The model and parameter estimates are shown in table A1 in the appendix. The model specification showed to be significant at a satisfying statistical level and more than $70 \%$ of all estimated parameters are statistically significant. Curvature correctness was a posteriori checked for all observations: the estimated specification showed to be theoretically consistent for more than $90 \%$ of the observations in the samples. This means that a large range of the estimated efficiency frontier is relevant for the inference of policy measures. The applied bootstrapping based resampling procedures confirmed the statistical robustness of the estimated frontier. A likelihood ratio test confirmed the chosen functional form of a flexible translog (see table 2 , hypothesis ii). A constant returns to scale specification was significantly rejected for the model (see table 2, hypothesis i), and the significance of the stochastic frontier specification was confirmed (see table 2, hypothesis iii). Finally, the hypothesis of no joint significance of all efficiency effects was convincingly rejected for the frontier model (see table 2, hypothesis iv). According to the findings regarding the superior variable returns to scale specification we subsequently discuss the empirical findings based on this model specification.

Table 2. Likelihood-Ratio Tests

\begin{tabular}{lcccc}
\hline \multicolumn{1}{c}{ Hypothesis $^{\text {a }}$} & Degrees of freedom & $\lambda_{L R}$ & $\chi_{0.95}^{2}$ & Conclusion \\
\hline i) Constant returns to scale is adequate & 4 & 118.78 & 9.89 & Reject \\
ii) CobbDouglas specification is adequate & 6 & 375.66 & 12.59 & Reject \\
iii) Mean production function is adequate & 15 & 174.53 & 24.99 & Reject \\
iv) Joint efficiency effects are insignificant & 15 & 128.32 & 24.99 & Reject \\
\hline
\end{tabular}

a : $\lambda_{L R}$ is the value of the likelihood-ratio statistics; $\chi^{2}$ gives the critical values.

The results for the levels of technical efficiency as well as scale efficiency are summarized by table 3 and table 4 , and are illustrated by figure 1 . The results clearly indicate a higher estimated mean efficiency score of about $91 \%$ (with a standard deviation of 2.12) for farmers who applied ISFM to their hybrid maize compared to a mean efficiency score of about $79 \%$ (with a standard deviation of 7.42) for those farmers using chemical based soil fertility management practices. Given the significance of the difference in efficiency scores between the soil fertility management options $(\mathrm{P}<0.000)$, these results imply that the use of ISFM improves the technical efficiency in hybrid maize production among smallholder farmers. Translated into actual yield losses, farmers that use chemical based soil fertility management loose on average about $143 \mathrm{~kg} / \mathrm{ha}$ (ranging from $102-216 \mathrm{~kg} / \mathrm{ha}$ ) due to inefficiency compared to only about $58 \mathrm{~kg} / \mathrm{ha}(24-156 \mathrm{~kg} / \mathrm{ha})$ on average among farmers that use ISFM options ${ }^{12}$. This yield loss is particularly substantial for the

12 Actual yield loss is estimated as the difference between maximum attainable yield and actual yield per farmer. Maximum attainable yield is obtained by dividing the actual yield attained by individual farmers by their respective efficiency score. 
poor smallholder farmers because it constitutes over $31 \%$ of the average yield for those farmers using chemical based soil fertility management practices.

Table 3. Technical Efficiency Scores by Soil Fertility Management Option

\begin{tabular}{lccccc}
\hline \multirow{2}{*}{ Sample } & $\begin{array}{c}\text { Relative Efficiency } \\
\text { Mean }^{a}\end{array}$ & \multicolumn{4}{c}{ Range } \\
\cline { 3 - 6 } & 79.35 & $7.42^{* * *}$ & 40.86 & 82.19 & 109 \\
\hline Inorganic Fertilizer only & 91.00 & $2.12^{* * *}$ & 79.51 & 96.85 & 143 \\
ISFM & 86.66 & $6.05 * * *$ & 40.86 & 96.85 & 252 \\
Total &
\end{tabular}

a : all mean scores are significantly different at $(\mathrm{P}<0.000), *, * * * * *$ : significant at 10,5 , or $1 \%$ level.

Figure 1 gives a box diagram interpretation of the efficiency frontier results. For the total sample the mean efficiency score is about $87 \%$ (with a standard deviation of 6.05) leading to the conclusion that the empirical findings are highly consistent over the sample.

Figure 1. Maize Efficiency Scores

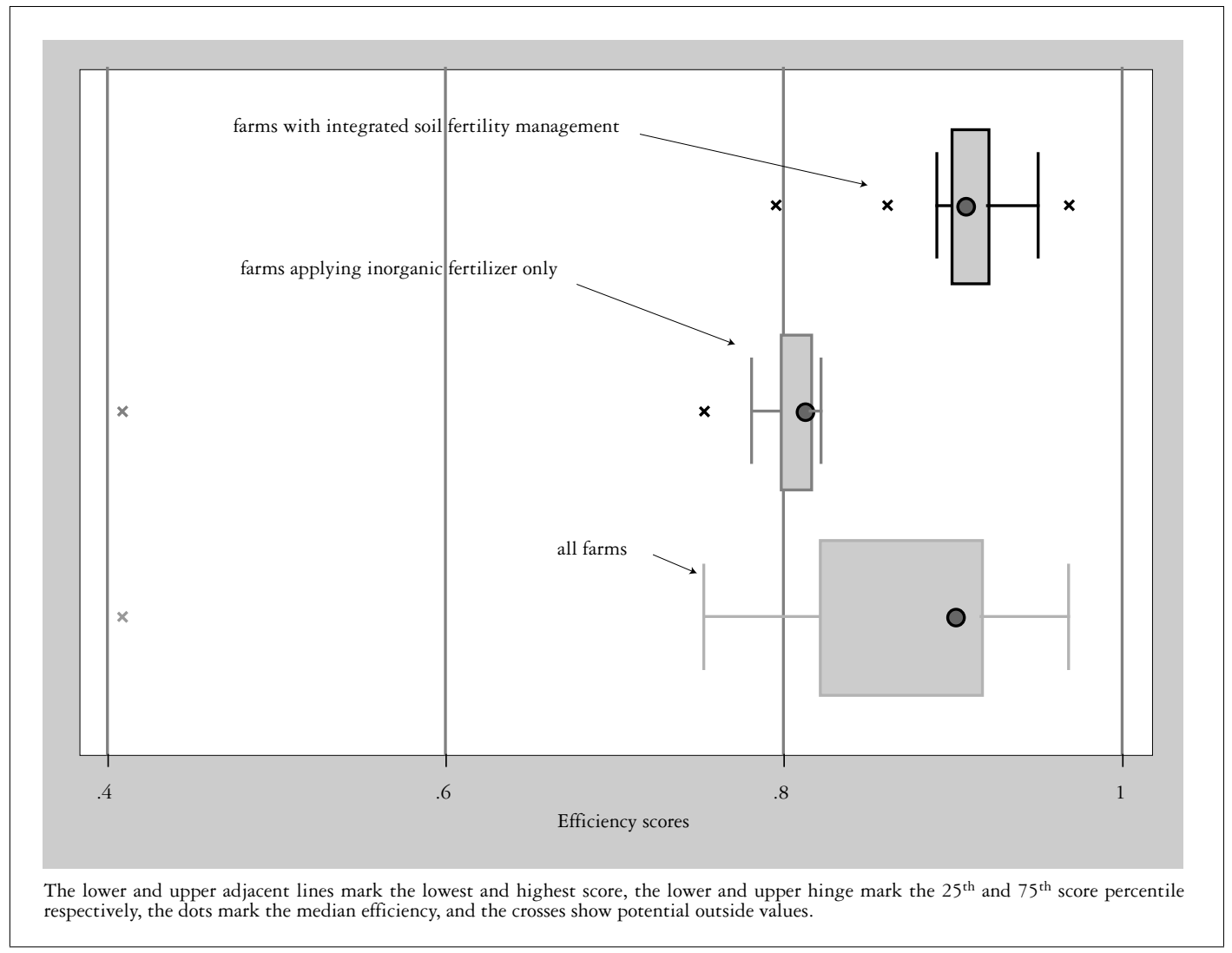


The positive impact of ISFM options on technical efficiency has been reported in many studies. For example, Ranamukhaarachchi and Rahman (2005) reported that the promotion of effective soil fertility management improved the technical efficiency of rice farmers in Bangladesh. Similarly, Weight and Kelly (1998) indicated that the performance of poor smallholder farmers in Sub-Saharan Africa can only be improved by a combination of chemical and organic based sources of soil fertility.

A soil fertility strategy exclusively based on one option is unlikely to work: While the nutrient content of chemical fertilizer is high and nutrient release patterns are rapid enough for plant growth, farmers are unlikely to afford optimal quantities. On the other hand, the quality and quantity of organic sources of fertility is often a deterrent with respect to the adoption of ISFM, especially in cases of highly nutrient deficient soils. Besides, the very high recommended quantities are associated with prohibitive labour demands which smallholder households can hardly satisfy. In the case of grain legumes, the process of biological nitrogen fixation is greatly compromised in the case of low soil fertility (Giller, 2001).

Table 4. Scale Efficiency Scores by Soil Fertility Management Option

\begin{tabular}{lccccc}
\hline \multirow{2}{*}{ Sample } & $\begin{array}{c}\text { Relative Efficiency } \\
\text { Mean }^{\text {a }}\end{array}$ & Std & Min. & Max. & Range \\
\cline { 3 - 6 } & 88.98 & $2.28^{* * *}$ & 63.33 & 92.46 & 109 \\
\hline Inorganic Fertilizer only & 95.89 & $2.37 * * *$ & 90.04 & 98.99 & 143 \\
ISFM & 94.73 & $4.71^{* * *}$ & 63.33 & 98.99 & 252 \\
Total &
\end{tabular}

a : all mean scores are significantly different at $(\mathrm{P}<0.000), *, * * * * *$ : significant at 10,5 , or $1 \%$ level.

The estimation results for the scale efficiency scores indicate that maize farmers applying integrated soil fertility practices are on average exhibiting a higher efficiency with respect to their scale of operations (see table 4) compared to those applying inorganic fertilizer only. Considerable economies of scale were found for the whole sample (a scale elasticity of about 1.008 to 1.120 at the sample mean) implying economic gains by further increasing maize production.

As the coefficients of the translog functional form allow no direct insight in the magnitude and significance of individual output elasticities, the latter were computed for all inputs at the sample mean (see table 5). We found the highest output elasticity with respect to land and the lowest output elasticity with respect to labor. These findings suggest that efficiency gains are most likely with respect to land and maize seed applied.

According to the results of the likelihood ratio test with respect to the joint significance of the inefficiency variation explaining factors (see table 2 , hypothesis $i v$ ) and assuming that the soil fertility management practice applied is adequately 
Table 5. Output Elasticities by Soil Fertility Management Option

\begin{tabular}{|c|c|c|c|c|c|}
\hline \multirow{2}{*}{ Sample } & \multirow{2}{*}{$\begin{array}{l}\text { Labor } \\
\text { Mean Elasticity }\end{array}$} & \multicolumn{4}{|c|}{ Range } \\
\hline & & Std & Min. & Max. & $N$ \\
\hline Inorganic Fertilizer only & 0.102 & $0.027 * * *$ & 0.024 & 0.159 & 109 \\
\hline ISFM & 0.067 & $0.047 *$ & 0.005 & 0.147 & 143 \\
\hline \multirow[t]{2}{*}{ Total } & 0.079 & $0.023 * * *$ & 0.001 & 0.159 & 252 \\
\hline & Fertilizer & \multicolumn{4}{|c|}{ Range } \\
\hline Sample & Mean Elasticity a & Std & Min. & Max. & $N$ \\
\hline Inorganic Fertilizer only & 0.225 & $0.009 * * *$ & 0.204 & 0.253 & 109 \\
\hline ISFM & 0.265 & $0.013 * * *$ & 0.223 & 0.289 & 143 \\
\hline \multirow[t]{2}{*}{ Total } & 0.245 & $0.023 * * *$ & 0.204 & 0.245 & 252 \\
\hline & Seed & \multicolumn{4}{|c|}{ Range } \\
\hline Sample & Mean Elasticity ${ }^{a}$ & Std & Min. & Max. & $\mathrm{N}$ \\
\hline Inorganic Fertilizer only & 0.564 & $0.036 * * *$ & 0.461 & 0.677 & 109 \\
\hline ISFM & 0.698 & $0.323 * *$ & 0.463 & 1.349 & 143 \\
\hline \multirow{3}{*}{ Sample } & 0.640 & $0.252 * * *$ & 0.461 & 1.349 & 252 \\
\hline & Land & \multicolumn{4}{|c|}{ Range } \\
\hline & Mean Elasticity ${ }^{a}$ & Std & Min. & Max. & $\mathrm{N}$ \\
\hline Inorganic Fertilizer only & 0.763 & $0.068 * * *$ & 0.579 & 0.763 & 109 \\
\hline ISFM & 0.899 & $0.081 * * *$ & 0.598 & 1.061 & 143 \\
\hline Total & 0.841 & $0.101 * * *$ & 0.579 & 1.061 & 252 \\
\hline
\end{tabular}

a : all mean scores are significantly different at $(\mathrm{P}<0.000), *, * * * * *$ : significant at 10,5 , or $1 \%$ level.

modelled by an inefficiency explaining factor we found indeed a significant positive effect of integrated practices with respect to the technical efficiency of the maize farm. As expected, the amount of rainfall experienced by the specific plot significantly influences the efficiency of maize production as more yield can be achieved per input used. With respect to the prevailing soil characteristics the empirical results show that the depth of the upper soil usable for agronomic activities positively affects the efficiency of maize cultivation. However, we found a detrimental impact of intercropping techniques on efficiency which is not in line with usual agronomic expectations. Nevertheless, early planting reduces the level of technical inefficiency and is significant at a $5 \%$ level of confidence. According to agronomic recommendations, early planting enhances yields by ensuring vigorous establishment of the crop with the first rains as well as increasing the chances that the crop will complete its physiological growth process before the cessation of the 
rain. Likewise, weeding is an important husbandry practice and low weeding frequency is known to result in substantial yield losses. By using simulation modeling Keating et al. (2000) have shown that investment in weeding could be equivalent to investing in a $50 \mathrm{~kg}$ bag of $\mathrm{N}$ fertilizer (such as ammonium nitrate) as it lowers the competition between the crop and weeds on soil water and nutrients. Although the actual economic yield losses from low weeding would be varying depending on a range of factors such as seasonal rainfall, soil fertility, weed pressure and type, it has been estimated to be as much as $25 \%$ on average for Malawi (Kumwenda et al., 1997). We tested also for the significance of cross-variable effects with respect to integrated soil fertility management and found a significant positive effect on maize production efficiency for the cross influences of integrated practices and the quantity of manure applied. This is additional empirical evidence for the efficiency improving effects of an integrative use of inherent soil nutrient stocks, locally available soil amendments and mineral fertilizers to increase the overall productivity of the land while maintaining or enhancing soil fertility. The manure applied increases the soil organic matter status and buffers against detrimental effects of inorganic fertilizer which nevertheless provides the necessary plants' nutrients and enhances the organic matters contained. All different kinds of manure applied (i.e. animal manure, green manure, and compost manure) showed the expected efficiency enhancing sign. However, statistically significant estimates have been only found for compost manure as well as the cross effects with respect to integrated soil fertility management for animal manure and compost manure.

The selected policy variables show the expected positive effect on technical efficiency. Access to input and output markets, a high frequency of extension services, and an effective access to credit services provide efficiency enhancing starting points. The significant effect of credit access may reflect the low levels of farmers access to credit among smallholder farmers, most likely due to collateral requirements and high interest rates associated with seasonal agricultural loans from the Malawi Rural Finance Company. In addition, seasonal lending for maize production is still unlikely to meet demand because of concerns among credit institutions that maize is a high-risk crop. Testing again for the significance of crossvariable effects with respect to integrated soil fertility management we further found a significant positive effect on maize production efficiency for the cross influences of integrated practices and the frequency of extension services offered/used. The adoption and effective implementation of integrated soil fertility management practices builds on the availability of comprehensive extension advice. It is worthwhile to note that the coefficient for the efficiency effect of extension frequency in conjunction with ISFM is remarkably higher than the coefficient for using extension services in general. Finally maize producing farms located in the agricultural development division of Lilongwe show on average a significantly higher technical efficiency than those located in the agricultural development division of Blantyre and Mzuzu (as the reference ADD). This could be due to the more favourable climatic and soil conditions prevailing in the region of Lilongwe compared to Blantyre and Mzuzu. 


\section{Conclusions and recommendations}

This paper explores the relative efficiency of maize producing farms in Malawi by particularly focusing the efficiency impact of integrated soil fertility management practices compared to the use of inorganic fertilizer only. Due to the existing literature this has not been investigated so far. Our empirical analysis revealed that farms applying integrated soil fertility management practices show a higher technical efficiency than farms applying inorganic fertilizer only (hypothesis 1). Considerable scale inefficiencies were found for the farms in the sample (hypothesis 2 ) and the analysis showed significant effects of soil fertility management practices as well as the prevailing soil and precipitation conditions on the efficiency of maize production (hypothesis 3). The statistical model tests finally confirmed our initial modeling assumption that the effect of the soil fertility practice applied is more adequately modelled by incorporating an efficiency explaining variable (hypothesis 4).

It became evident that ISFM options provide an effective scope for improving the efficiency of smallholder farmers by ensuring increased output (up to $31 \%$ for farmers using chemical based soil fertility management practices). This is linked to the need for an improvement in access to credit facilities: In order to ensure an effective establishment of ISFM, farmers need to consistently use hybrid maize, grain legume seed and fertilizer which require financial outlays that farmers can hardly afford without the assurance of expected benefits. The role of policy is to ensure the appropriate provision of agricultural credit, extension services and general infrastructural endowments. Safety-nets such as food for work or fertilizer for work have been considered as successful because they simultaneously address a number of problems that affect smallholder farmers. The development of rural markets by providing effective public infrastructure reduces traders' transactions costs and creates favourable demand prospects for grain legumes such as groundnuts, soybeans and pigeonpeas and thereby motivating farmers to grow these soil fertility 'best-bet' crops used in the course of integrated soil fertility management. Given finally the existence of alternative policy options, due to our analysis the Malawian government should focus on strengthening the effectiveness of extension services with respect to integrated soil fertility management: the provision of such services is beside integrated soil management and public infrastructure endowment a crucial factor for the enhancement of maize production efficiency. The creation of rural networks including NGOs could provide an opportunity for an effective improvement in extension service delivery in the future.

\section{References}

Alderman H., Hoddinott J., Haddad L. and Udry C. (1995). Gender differentials in farm productivity: Implications for household efficiency and agricultural policy, Food Consumption and Nutrition Division, Discussion paper, ${ }^{\circ} 6$, International Food Policy Research Institute.

Barrett C.B. (1997). How credible are estimates of peasant allocative, scale or scope efficiency? A commentary, Journal of International Development, 9, pp. 221-229. 
Battese G.E., Coelli T.J. (1995). A model for technical inefficiency effects in a stochastic frontier production function for panel data, Empirical Economics, 20, pp. 325-332.

Bhalla A., Chipeta C., Taye H. and Mkandawire M. (2000). Globalization and sustainable human development: Progress and challenges for Malawi, Occasional paper, UNCTAD/UNDP.

Breman H., Sissoko K. (eds) (1998). L'intensification agricole au sabel, Paris, Karthala.

Charnes A., Cooper W. and Rhodes E. (1978). Measuring the efficiency of decisionmaking units, European Journal of Operations Research, 2 (6), pp. 429-444.

Chambers R. (1988). Applied Production Analysis: A Dual Approach, Cambridge, Cambridge University Press.

Chirwa E.W. (2003). Sources of technical efficiency among smallholder maize farmers in Southern Malawi, Department of Economics, Chancellor College, Zomba, Malawi.

Coelli T., Prasado R. and Battese N. (1998). An Introduction to Efficiency and Productivity Analysis, Boston, Kluwer Academic Press.

Debreu G. (1951). The coefficient of resource utilization, Econometrica, 19(3), pp. 273-292.

Debreu G. (1959). Theory of Value, New York, Wiley.

Dorward A., Kydd J., Morrison J. and Urey I. (2004a). A policy agenda for pro-poor agricultural growth, World Development, 32(1), pp. 73-89.

Dorward A., Wobst P., Lofgren H., Tchale H. and Morrison J. (2004b). Modeling pro-poor agricultural growth strategies in Malawi. Lessons for policy and analysis. (manuscript)

Edriss A., Tchale H. and Wobst P. (2004). The impact of labour market liberalization on maize productivity and rural poverty in Malawi, Working paper, Policy analysis for sustainable agricultural development (PASAD), Center for Development Research, University of Bonn, Germany.

Efron B. (1979). Bootstrap methods: Another look at the Jackknife, Annals of Statistics, 7, pp. 1-26.

Efron B., Tibshirani R.J. (1993). An Introduction to the Bootstrap, London, Chapman \& Hall.

Fozzard F., Simwaka C. (2002). How, when and why does poverty get budget priority: Poverty reduction strategy and public expenditure in Malawi, Overseas Development Institute.

Fulginiti L.E., Perrin R.K. (1998). Agricultural productivity in developing countries, Agricultural Economics, 19 (1-2), pp. 45-51.

Giller K.E. (2001). Nitrogen Fixation in Tropical Cropping Systems, $2^{\text {nd }}$ ed., Wallingford, CAB International, $423 \mathrm{p}$. 
Government of Malawi (GOM) (2002). Qualitative impact monitoring (QIM) of poverty alleviation policies and programmes: Survey findings, Lilongwe, National Economic Council.

Helfand S.M., Levine E.S. (2004). Farm size and determinants of productive efficiency in the Brazilian Center-West, Agricultural Economics, 31, pp. 241-249.

Heshmati A., Mulugeta Y. (1996). Technical efficiency of the Ugandan matoke farms, Applied Economic Letters, 3, pp. 491-494.

Heisey P.W., Smale M. (1995). Maize technology in Malawi. A green revolution in the making ?, CIMMYT Research Report, n 4, Mexico City, Mexico.

Horowitz J.L. (2001). The Bootstrap, in: Handbook of Econometrics, Heckman J.J., Leamer E. (eds), vol. 5, pp. 3159-3228, Amsterdam, North-Holland.

Kalaitzadonakes N.G., Wu S. and Ma J.C. (1992). The relationship between technical efficiency and firm size revisited, Canadian Journal of Agricultural Economics, 40, pp. $427-442$.

Karagiannis G., Sarris A. (2005). Measuring and explaining scale efficiency with the parametric approach: The case of Greek tobacco growers, Agricultural Economics, 33, pp. 441-451.

Keating B.A., Waddington S., Grace P., Rohrbach D., Dimes J., Shamudzarira Z., Carberry P. and Robertson M. (2000). Exploring farmer options for maize production strategies via scenario analyses using the APSIM model - an example of the approach SOILFERTNET/CIMMYT, Risk Management Working paper Series, $n^{\circ}$ 2000/02.

Kumwenda J.D.T., Waddington S.R., Snapp S.S., Jones R.B. and Blackie M.J. (1997). Soil fertility management in the smallholder maize-based cropping systems of Africa, in: The Emerging Maize Revolution in Africa: The Role of Technology, Institution and Policy, East Lansing, Michigan State University.

Kumbhakar S.C., Lovell C.A.K. (2000). Stochastic Frontier Analysis, Cambridge, Cambridge University Press.

Kydd J. (1989). Maize research in Malawi: Lessons from failure, Journal of International Development, 1(1), pp. 112-144.

Kydd J., Dorward A. (2001). The Washington Consensus on poor country agriculture: Analysis, prescription and institutional gaps, Development Policy Review, 19(4), pp. 467-478.

Mochobelele M.T., Winter-Nelson A. (2000). Migrant labour and farm technical efficiency in Lesotho, World Development, 28(1), pp. 143-153.

Okike M., Jabbar A., Manyong V.M., Smith J.W. and Ehui S.K. (2004). Factors affecting farm-specific production efficiency in the Savanna Zones of West Africa, Journal of African Economies, 13(1), pp. 134-165.

Owusu K., Ngambi F. (2002). Structural damage: The causes and consequences of Malawi's food crisis, London, World Development Movement. 
Pieri C. (1989). Fertility of Soils: A future for Farming in the West African Savannah, Berlin, Springer-Verlag.

Ranamukhaarachchi S.L., Rahman M.M. (2005). Soil fertility and land productivity under different cropping systems in highlands and medium highlands of Chandina sub-district, Bangladesh, Asia-Pacific Journal of Rural Development, $\mathrm{XV}(1)$, pp. 63-76.

Reinhard S., Lovell C.A.K., and Thijssen G.J. (2002). Analysis of environmental efficiency variation, American Journal of Agricultural Economics, 84(4), pp. 10541065.

Sauer J. (2006). Economic theory and econometric practice: Parametric efficiency analysis, Empirical Economics, 31, pp. 1061-1087.

Schultz T.W. (1964). Transforming Traditional Agriculture, Chicago, University of Chicago Press.

Seyoum E.T., Battese G.E. and Fleming E.M. (1998). Technical efficiency and productivity of maize producers in Eastern Ethiopia: A survey of farmers within and outside Sasakawa-Global 2000 Project, Agricultural Economics, 19, pp. 341-348.

Sherlund S.M., Barrett C.B. and Adesina A.A. (2002). Smallholder technical efficiency controlling for environmental production conditions, Journal of Development Economics, 69, pp. 85-101.

Smale M., Jayne T. (2003). Maize in Eastern and Southern Africa: Seeds of success in retrospect, Environment and Production Technology Division, Discussion paper, $n^{\circ}$ 97, International Food Policy Research Institute, Washington D.C.

Tian W., Wan G.H. (2000). Technical efficiency and its determinants in Chinese grain production, Journal of Productivity Analysis, 2000(13), pp. 159-174.

Townsend R.F., Kirsten R.F. and Vink N. (1998). Farm size, productivity and returns to scale in agriculture revisited: A case study of wine producers in South Africa, Agricultural Economics, 19, pp. 175-180.

Weir S. (1999). The effects of education on farmer productivity in rural Ethiopia, Working paper CSAE WPS99-7, Center for the Study of African Economies, University of Oxford.

Weir S., Knight J. (2000). Education externalities in rural Ethiopia. Evidence from average and stochastic frontier production functions, Working paper CSAE WPS/2000-4, Center for the Study of African Economies, University of Oxford.

Weight D., Kelly V. (1998). Restoring soil fertility in Sub-Saharan Africa. Policy synthesis $n^{\circ} 37$, Office of Sustainable Development, United States Agency for International Development (USAID).

Zeller M., Diagne A. and Mataya C. (1998). Market access by smallholder farmers in Malawi: Implications for technology adoption, agricultural productivity and crop income, Agricultural Economics,19, pp. 219-229. 


\section{APPENDIX}

Table A1. Bias-Corrected Bootstrapped Translog Production Frontier

\begin{tabular}{|c|c|c|c|}
\hline Variable & Coeff. & Std Err. ${ }^{a}$ & $\begin{array}{c}\text { Bias Corrected } 95 \% \\
\text { Conf. Interval }\end{array}$ \\
\hline \multicolumn{4}{|l|}{ Maize output } \\
\hline Labor & 0.545 & $0.327 *$ & {$[0.336 ; 1.242]$} \\
\hline Fertilizer & 0.489 & $0.039 * * *$ & {$[0.377 ; 0.561]$} \\
\hline Seed & 0.841 & $0.110 * * *$ & {$[0.707 ; 1.412]$} \\
\hline Land & -0.822 & $0.119 * * *$ & {$[-1.543 ;-0.657]$} \\
\hline Labor2 & 0.045 & $0.026 *$ & {$[0.006 ; 0.094]$} \\
\hline Fertilizer2 & 0.025 & $0.001 * * *$ & {$[0.022 ; 0.026]$} \\
\hline Seed2 & -0.744 & $0.145 * * *$ & {$[-1.477 ;-0.553]$} \\
\hline Land2 & -0.816 & $0.167 * * *$ & {$[-1.922 ;-0.607]$} \\
\hline Labor x fertilizer & 0.007 & $0.003^{* *}$ & {$[0.003 ; 0.012]$} \\
\hline Labour $\mathrm{x}$ seed & -0.264 & $0.095 * * *$ & {$[-0.408 ;-0.052]$} \\
\hline Labour $\mathrm{x}$ land & 0.219 & $0.095 * *$ & {$[0.136 ; 0.417]$} \\
\hline Fertilizer $\mathrm{x}$ seed & 0.002 & 0.008 & {$[-0.015 ; 0.011]$} \\
\hline Fertilizer $x$ land & -0.056 & $0.007 * * *$ & {$[-0.063 ;-0.039]$} \\
\hline Seed $x$ land & 1.617 & $0.289 * * *$ & {$[1.201 ; 3.559]$} \\
\hline Intercept & -15.571 & $2.319 * * *$ & {$[-20.116 ;-11.025]$} \\
\hline \multicolumn{4}{|l|}{$\operatorname{lnsig} 2 v$} \\
\hline Intercept & -3.967 & $0.189 * * *$ & {$[-4.338 ;-3.596]$} \\
\hline \multicolumn{4}{|l|}{ Insig2u } \\
\hline Sfm & -2.833 & $0.189 * * *$ & {$[-3.204 ;-2.462]$} \\
\hline Rainfall & -0.020 & $0.015^{*}$ & {$[-0.060 ; 0.031]$} \\
\hline Weeding & -0.484 & $0.138 * * *$ & {$[-0.754 ;-0.213]$} \\
\hline Planting date & -0.268 & $0.033 * *$ & {$[-0.385 ; 0.921]$} \\
\hline Market access & -0.859 & $0.210 * * *$ & {$[-1.271 ;-0.448]$} \\
\hline Extension frequency & -0.174 & $0.104^{*}$ & {$[-0.377 ; 0.029]$} \\
\hline Credit access & -0.399 & $0.192 * *$ & {$[-0.775 ;-0.023]$} \\
\hline Soil depth & -0.108 & $0.056 * *$ & {$[-0.001 ; 0.217]$} \\
\hline Bulk density & 0.639 & $0.374^{*}$ & {$[-0.093 ; 1.372]$} \\
\hline
\end{tabular}


Table A1. Bias-Corrected Bootstrapped Translog Production Frontier

\begin{tabular}{|c|c|c|c|}
\hline Variable & Coeff. & Std Err. ${ }^{\text {a }}$ & $\begin{array}{l}\text { Bias Corrected } 95 \% \\
\text { Conf. Interval }\end{array}$ \\
\hline Organic matters & -0.602 & $0.318^{*}$ & {$[-1.226 ; 0.022]$} \\
\hline Total nitrogen & -3.913 & 3.043 & {$[-2.051 ; 9.877]$} \\
\hline Cropping pattern & 0.682 & $0.255 * * *$ & {$[0.183 ; 1.182]$} \\
\hline Animal manure & -0.665 & 1.112 & {$[-2.845 ; 1.515]$} \\
\hline Preen manure & -0.657 & 1.258 & {$[-3.123 ; 1.809]$} \\
\hline Compost manure & -1.191 & $0.708^{*}$ & {$[-2.579 ; 0.198]$} \\
\hline Manure quantity & -0.099 & 0.102 & {$[-0.298 ; 0.100]$} \\
\hline Agr. dev. div. Lilongwe & -0.794 & $0.339 * *$ & {$[-1.459 ;-0.129]$} \\
\hline Agr. dev. div. Blantyre & 0.493 & $0.289 *$ & {$[-0.034 ; 1.019]$} \\
\hline Sfm $x$ extension frequency & -0.814 & 0.695 & {$[-2.176 ; 0.548]$} \\
\hline Sfm x manure quantity & -3.011 & $1.885^{*}$ & {$[-6.706 ; 0.685]$} \\
\hline Sfm $x$ animal manure & -2.783 & $0.872 * * *$ & {$[-4.493 ;-1.072]$} \\
\hline Sfm $x$ green manure & -0.727 & 0.976 & {$[-2.642 ; 1.187]$} \\
\hline Sfm $x$ compost manure & -1.185 & $0.501 * *$ & {$[-2.167 ;-0.202]$} \\
\hline Sex of the farmer & -0.064 & 0.316 & {$[-0.685 ; 0.556]$} \\
\hline Age of the farmer & 0.008 & 0.007 & {$[-0.008 ; 0.025]$} \\
\hline Education of the farmer & 0.066 & 0.109 & {$[-0.149 ; 0.279]$} \\
\hline Size of the household & -0.039 & 0.062 & {$[-0.160 ; 0.081]$} \\
\hline Intercept & -3.308 & $0.292 * * *$ & {$[-3.879 ;-2.736]$} \\
\hline Sigma_v & 0.137 & $0.013 * * *$ & {$[0.114 ; 0.166]$} \\
\hline Wald Chi-square Stat. & 15693.25 & & \\
\hline Prob $>$ Chi-square & 0.000 & & \\
\hline $\mathrm{N}$ of obs. & 252 & & \\
\hline Log. Likelihood & 77.896 & & \\
\hline Replications & 1000 & & \\
\hline Consistency Range of Estimated Frontier (in \%) & 95 & & \\
\hline
\end{tabular}

a : ***,***: significant at 10,5 , or $1 \%$ level. 